DOI 10.12737/article_5db989590e8410.34997140

УДК 332.1, 311.313

ОСОБЕННОСТИ РАЗВИТИЯ ХОЗЯЙСТВУЮЩИХ СУБЪЕКТОВ В РОССИЙСКИХ РЕГИОНАХ (НА ПРИМЕРЕ РЕСПУБЛИКИ ТАТАРСТАН И ПЕНЗЕНСКОЙ ОБЛАСТИ) Габдрахманова Г.Ф., Сагдиева Э.А.

Реферат. Современное разнообразие аграрного сектора в субъектах РФ стимулирует дальнейшую оптимизацию решений в области управления территориями страны. Региональная дифференциация во многом связана с приоритетами хозяйствующих субъектов при формировании сельскохозяйственной политики. В статье сформулирована гипотеза и приводятся аргументы, показывающие, что между Всероссийскими сельскохозяйственными переписями 2006 и 2016 гг. произошло дальнейшее углубление различий в сельской отрасли регионов РФ. Это проявляется в перераспределении производственных специализаций и в развитии ресурсного потенциала хозяйствующих субъектов. Авторы приводят результаты Всероссийских переписей населения 2006 г. и 2016 г. в Республике Татарстан и Пензенской области. Ими подсчитаны относительные показатели сельскохозяйственной деятельности сельскохозяйственных организаций, крестьянскофермерских хозяйств и личных подсобных хозяйств в данных субъектах РФ. Выявлено, что для Татарстана характерна мягкая интенсификация сельского хозяйства и политика укрепления всех хозяйствующих субъектов. В Пензенской области наблюдается их сокращение и ускоренное развитие некоторых субъектов. В ней сохранившиеся хозяйствующие субъекты стали более экономически состоятельными. Сравнение регионов выявило углубление их производственных специализаций. Они похожи и в том, что сельское предпринимательство так и не стало весомым участником сельскохозяйственной отрасли, хотя налицо рост оснащенности его техникой.

Ключевые слова: Республика Татарстан, Пензенская область, Всероссийская сельскохозяйственная перепись, ресурсы, сельскохозяйственная организация, крестьянско-фермерское хозяйство, личное подсобное хозяйство.

Введение. Сельскохозяйственные переписи РФ проводятся с целью формирования статистической информации о наличии и об использовании ресурсного потенциала сельского хозяйства [1]. Их материалы подвергаются анализу [2; 3], в том числе зарубежными учеными [4; 5]. Интересными выглядят исследования о развитии сельского хозяйства в субъектах РФ [6; 7]. Немногочисленность последних требует углубления научных знаний о происходящих процессах в сельскохозяйственной отрасли отдельных территорий.

Цель статьи - рассмотреть в региональном разрезе изменения между 2006 и 2016 гг. в ресурсном потенциале и производственных специализациях субъектов сельскохозяйственной отрасли.

Условия, материалы и методы исследований. В исследовании применен сравнительный метод, позволивший сопоставить данные Всероссийских сельскохозяйственных переписей 2006 и 2016 гг. [8; 9] об использовании трудовых и земельных ресурсов, о производственных специализациях сельскохозяйственных организаций (CXO); крестьянских (фермерских) хозяйств (КФХ); личных подсобных хозяйств (ЛПХ).

Республика Татарстан (РТ) и Пензенская область (ПО) входят в Приволжский Федеральный округ. РТ, производя в 2015 г. 18,6\% объема сельскохозяйственной продукции ПФО, занимала лидирующие позиции. ПО заметно отстает, хотя за последнее десятиле- тие продемонстрировала положительную динамику в сельскохозяйственной отрасли (2006 г. - 17,9 млрд руб., 2015 г. - 80,6; РТ - 71,6 и 213,7) [10]. Сравнение регионов позволяет сформировать практические рекомендации для оптимизации проводимой ими сельскохозяйственной политики на основе положительного опыта соседнего региона.

Анализ и обсуждение результатов исследований. В 2000-х гг. в регионах развивались разнонаправленные тенденции в численности хозяйствующих субъектов (ХC). В РТ происходил их рост (2006 - 531669, 2016 - 576021), в ПО - сокращение (334664 и 319498). Основными ХС являются ЛПХ (около 99\%). Их доля увеличилась, но положительные тенденции наблюдаются лишь в РТ (рост на 44856). В ПО сокращение на 13184 единицы. КФХ составляют не более $1 \%$. Положительные тенденции наблюдаются в РТ: их число увеличилось на четверть (на 686). В ПО сократилось более чем в два раза (на 1384).

Переписи зафиксировали менее $1 \%$ СХО. Их количество сократилось и в РТ (на 1053 единицы), и в ПО (232). В аграрном секторе РТ произошло увеличение численности ХC (за счет ЛПХ), а в ПО - их сокращение. Общим стало незначительное участие в развитии сельского хозяйства КФХ и СХО. Несмотря на некоторый рост КФХ в Татарстане, они не стали заметными участниками сельскохозяйственной отрасли республики.

Объем земельных площадей в РТ в два 
раза больше, чем в ПО (2006 г. - 4441614 га, 2016 - 4197447; 2680665 и 2176106). Несмотря на их сокращение, темпы данной тенденции в РТ более замедленные (на 6\% или на 244167,4 га), чем в ПО (19\% или 504559), а значит ХС Татарстана используют землю более активно.

В землепользовании снижается роль крупных ХС. СХО обладали в 2006 г. в РТ 85\% земельной площади, 2016 - 81\%; ПО - 87\% и 76\%. Увеличиваются земельные ресурсы у КФХ (РТ в 2006 г. - 13\%, 2016 - 18\%; ПО $10 \%$ и 19\%) и ЛПХ (РТ в 2006 г. - 3\%, 2016 $5 \%$; ПО - 3\% и 5\%). Этот процесс активнее развивается в ПО, чем в РТ. Если КФХ РТ увеличили объемы земли на 106496,5 га (21\%), ЛПХ - 33882,5 га (29\%), то в ПО - на 143312,5 га (54\%) и 33179,5 га (43\%). В ПО, несмотря на то, что как указано выше, число КФХ и ЛПХ ниже, чем в РТ, они за межпереписной период накопили больше земли, а значит стали более экономически состоятельными ХC.

Уменьшение значения СХО и усиление роли мелких ХС (особенно в ПО) прослеживается по показателю объемов их посевных площадей. В 2006 г. на долю СХО в Татарстане приходилось 85\% посевных площадей республики, КФХ - 12\%, ЛПХ - 3\%; ПО - 84\%, 11\%, 4\%. В 2016 г. СХО РТ обладали 81\% посевныХ земель, КФХ - 16\%, ЛПХ - 4\%; ПО - 72\%, $24 \%, 4 \%$. В ПО происходила более активная передача земли в КФХ, чем в РТ.

В СХО и КФХ РТ трудилось в три раза больше населения (2006 - 131714 чел., 2016 67627), чем в ПО (42267 и 22313). Но Татарстан испытал более значительные потери (64087 чел., ПО - 19954).

Основные трудовые ресурсы сосредоточены в СХО: в РТ в 2006 г. - 89\% или 117786 чел., занятых в ХС региона, ПО - 86\% (36206). К 2016 г. картина не изменилась: в РТ задействовано 86\% трудовых ресурсов, ПО - 84\%. Абсолютные данные показывают снижение работающих в СХО в два раза (РТ до 58786 чел., ПО - 18694), и особенно сильно в Татарстане (на 59000 чел., ПО - 17512).

Тенденция сокращения трудовых ресурсов коснулась и КФХ. Она проявилась лишь в абсолютном выражении: в данных организациях в 2006 г. в РТ трудилось 13928 человек занятых сельскохозяйственных трудом (11\% от общего числа работников ХС), 2016 - 8841 (13\%). В ПО эти показатели в 2006 г. - 6061 чел. (14\%), 2016 - 3619 (16\%).

Несмотря на одинаковое снижение численности занятых в СХО и КФХ в анализируемых регионах, их потери в абсолютных значениях в целом были ниже в Татарстане. Ситуация в республике выглядит сравнительно лучше и по общей численности трудовых ресурсов, задействованных в сфере сельского хозяйства.

Фиксируемое сокращение занятых в сельском хозяйстве свидетельствует об увеличении производительности аграрного труда, оснащенности техникой. ПО уступает РТ по динамике количества тракторов (в РТ рост на $5 \%$; ПО сокращение на 14\%), грузовых и грузопассажирских автомобилей (в РТ увеличение на 23\%; ПО убыль на $11 \%$ ), доильных установок (в РТ их стало больше почти в четыре раза, ПО - на 46\%); мотоблоков и мотокультиваторов (в РТ увеличилось в 11 раз, ПО - в четыре с половиной раза). В регионах произошло сокращение числа зерно-, кукурузо-, кормо-, свеклоуборочных комбайнов (особенно в ПО, в которой, однако, в два раза увеличилось количество картофелеуборочных комбайнов).

Произошли изменения в технической оснащенности ХC. Тракторами стали активнее пользоваться некрупные производители, аккумулировавшие к 2016 г.: КФХ - 13\% в РТ и $16 \%$ в ПО, ЛПХ - 52\% и $60 \%$ данной техники. Им стали проигрывать СХО, которые в 2006 г. занимали лидирующие позиции: в РТ в их владении находилось $61 \%$ тракторов региона, ПО - 44\%. К 2016 г. показатель сократился до $35 \%$ в РТ (на $40 \%$ ) и до $25 \%$ в ПО (на 49\%). СХО обладают в РТ в 2006 г. - 80\%, 2016 $68 \%$; ПО - 74\% и 52\% комбайнов региона, хотя КФХ наращивают их парк (РТ в 2006 г. $20 \%, 2016$ - 33\%; ПО - 27\% и 48\%). Такая же тенденция и по оснащенности косилками, плугами и сеялками. Что касается доильных установок, то их основными обладателями стали ЛПХ (в РТ они имели в 2006 г. 8\% данной техники, 2016 - 83\%, ПО - 16\% и 74\%). Число доильных установок в ЛПХ РТ выросло в более чем в пятьдесят раз, ПО - в пять. Зафиксирован рост количества мотоблоков и мотокультиваторов в ЛПХ (в РТ в тринадцать раз, ПО - в пять), а также грузовых и грузопассажирских автомобилей (в РТ в два раза, ПО - на $6 \%$ ).

Можно сделать заключение о более высоких темпах механизации сельского хозяйства в РТ, чем ПО. Общей тенденций для регионов стало повышение оснащенности техникой КФХ и ЛПХ, что может свидетельствовать об укреплении их экономического положения. Данные об изменениях в оснащенности разными видами агротехники ХC демонстрируют складывающуюся многоукладность сельского хозяйства, связанную с их производственными специализациями.

Оба региона специализируются на производстве зерновых и зернобобовых культур. Площади под них в РТ сохранились (2006 г. 54\% всей посевной площади региона, 2016 $52 \%$ ), а в ПО сократились (с $60 \%$ до $54 \%$ ). В 
РТ сохранились площади под технические и кормовые культуры. Увеличилось производство масличных культур (в два раза). ПО нарастила производство технических культур (с 9\% и 28\%), масличных (с 5\% до 24\%), снизив кормовых (с 27\% до 15\%).

В растениеводстве наблюдается снижение роли СХО и усиление КФХ. В ПО этот процесс более интенсивный. В КФХ ПО объемы посевных площадей под зерновые и зернобобовые культуры выросли на $64 \%$, в Татарстане на $33 \%$, хотя в абсолютных значениях республика является лидером (75029,8 га против 63252,9 га в ПО). КФХ РТ уступают КФХ ПО в производстве технических (в РТ - прирост составил 16690,6 га; ПО - 70490), кормовых $(30033,8$ и 34981,7$)$ и масленичных $(12782$ и 71802,5) культур.

Производство картофеля и овощей сосредоточено в ЛПХ. Несмотря на сокращение объемов (в РТ на 14336 га; ПО - 304792), их вклад увеличивается (в РТ с 75\% до 80\%; ПО - с $81 \%$ до $86 \%$ ).

Производство крупного рогатого скота демонстрировало отрицательную динамику. Особенно сильное падение наблюдалось в ПО - сокращение на 46\% (на 151354 головы), РТ $11 \%(124964)$.

Основной вклад в производство КРС вносят СХО: в них в 2006 г. содержалось 66\% от всего производимого в РТ, $2016-63 \%$ (ПО $43 \%$ и 41\%). В ЛПХ и КФХ РТ этот показатель не изменился, а в ПО упал (с 55\% до 44\%) за счет наращивания производства в КФХ (2006 г. - 2\%, 2016 - 15\%). Данный ХС ПО нарастил производство до уровня Татарстана (19638 и 21223 голов).

Производство молочного КРС сократилось. Особенно сильно в ПО - на 164615 голов или на 50\%, в РТ - 185230 голов, 16\%. Главными производителями в РТ являются СХО (2006 г. - 66\%, 2016 - 63\%), в ПО - ЛПХ (55\% и 47\%). Второй участник в РТ - ЛПХ (2006 г. - 29\%, 2016 - 29\%), а в ПО - СХО (43\% и 41\%). На третьем месте - КФХ, вклад которых увеличивается, но особенно сильно в ПО (в пять раз).

В РТ и ПО наблюдается прирост поголовья мясных КРС, причем во всех категориях хозяйств. Упали объемы производства свинины, особенно в РТ (на 261394 головы или на 34\%, ПО - 62283 или 23\%). В РТ ее основное производство сосредоточено в СХО: в 2006 г. 79\% от всего их поголовья в республике, 2016 85\%. В ПО данный ХС в 2006 г. произвел пятую часть поголовья свиней. К 2016 г. этот показатель увеличился вдвое. КФХ занимают незначительный сегмент в производстве свинины. Снижается вклад ЛПХ, особенно в ПО

Снизились объемы содержания овец и коз
(РТ на $11 \%$, ПО - 22\%). В РТ в пять раз усилилась роль КФХ в их производстве. Упало поголовье лошадей (РТ на треть, ПО - в два раза). $60 \%$ лошадей в РТ в 2006 г. содержалось в CXO, 47\% - в 2016 г. В ПО их чаще выращивают в ЛПХ (84\% и 63\%).

Количество пчелосемей увеличилось лишь в РТ (на 45\%). В ПО сокращение на 6\%. Основным производителем меда в обоих регионах являются ЛПХ (РТ в 2006 г. - 68\%, 2016 $90 \%$; ПО - 93\% и 95\%).

Произошел рост производства сельскохозяйственной птицы. В ПО он более интенсивный: за 2006-2016 гг. в два раза (на 5112603 головы). В РТ - на 66\% (6896159). Основным производителем являются СХО и их вклад растет: в РТ в 2006 г. они вырастили 67\% от общего количества птицы в регионе, 2016 $71 \%$; ПО - 57\% и 85\%. Меньший вклад у ЛПХ и их участие сокращается: в РТ в 2006 г. они произвели $31 \%$ птицы, в ПО - 42\%; в 2016 г. $22 \%$ и $14 \%$. Что касается КФХ, то в РТ они наращивают производство (2006 г. - 2\%, 2016 - 7\%), а в ПО остаются на прежнем уровне $(1 \%)$.

Выводы. Обобщая данные ВСХП-2006 г. и ВСХП-2016 гг. следует отметить разные стратегии развития сельского хозяйства в рассматриваемых регионах. Для Татарстана характерна мягкая интенсификация данной отрасли и политика укрепления всех XC: на фоне увеличения их численности и разнообразия в республике, сохранения посевных площадей, а также укрепления технической оснащенности наблюдается более сглаженный вклад СХО, КФХ и ЛПХ в развитии растениеводства, производства мяса (включая птицу). Очевидно, на эту тенденцию оказывает влияние политика Татарстана, направленная на поддержку разных видов предпринимательства на селе в виде программ, предусматривающих выделение грантов и субсидий по различным направлениям сельского хозяйства и села в целом. Все это позволяет РТ демонстрировать не столь сильное падение показателей сельскохозяйственной отрасли, как в ПО.

В ПО наблюдается сокращение числа ХС и ускоренное развитие их отдельных форм. В период между переписями сохранившиеся ХC стали более экономически состоятельными (у них стало больше земли, включая посевную), заняли весомые (в сравнении с РТ) позиции (КФХ в растениеводстве, ЛПХ - выращивании картофеля и овощей) и даже монополизировали отдельные отрасли сельского хозяйства (CXO - в производстве курятины и индейки). По уровню механизации они уступают РТ. В ПО наблюдается более сильное снижение объемов КРС (включая молочное). Здесь в отличие от РТ сократились площади под засевы 
зерновых, зернобобовых, кормовых культур, картофеля, площади под многолетние плодовые насаждения и ягодные культуры.

Сравнение РТ и ПО выявило усиление производственных специализаций данных регионов. ПО стала больше специализироваться на производстве технических культур, овощных и бахчевых культур, курятины, индейки. В РТ наблюдается сильное сокращение производства свинины, увеличение поголовья овец, коз, уток. Наблюдается одинаковое стремление регионов к расширению ассортимента производимой птицы.
Для изучаемых регионов характерны и общие тенденции. Это сокращение количества работников, занятых в сельском хозяйстве, общих земельных площадей и отводимых под сельхозугодия, модернизация сельхозтехники и появление ее более высокотехнологичных моделей, поголовья молочных коров, значительное увеличение мясного КРС, развитие интереса к производству масленичных культур. РТ и ПО похоже и в том, что КФХ, ЛПХ и НКО так и не стали в них весомыми участниками сельскохозяйственной отрасли, хотя налицо рост оснащенности их техникой.

Литература

1. Федеральный закон от 21.07.2005 N 108-Ф3 (ред. от 01.12.2014) “О Всероссийской сельскохозяйственной переписи” [Электронный ресурс]: Консультант-плюс. - режим доступа: http://www.consultant.ru/ document/cons_doc_LAW_54521/

2. Бартова Е.В., Радостева Э.М., Галеев М.М. Значение сельскохозяйственной переписи для развития аграрного сектора экономики России // Экономика и предпринимательство. - 2015. - №6. - 3(59). - С. 104107.

3. Петриков А.В. Итоги Всероссийской сельскохозяйственной переписи 2016 года: основные структурные изменения в сельском хозяйстве России за 10 лет [Электронный ресурс] // Московский экономический журнал. - 2017. - №4. - режим доступа: http://qje.su/selskohozyajstvennye-nauki/moskovskij-ekonomicheskijzhurnal-4-2017-64/

4. Schierhorn F., Müller D., Prishchepov A., Faramarzic M., Balmann A. The potential of Russia to increase its wheat production through cropland expansion and intensification [Электронный pecypc] // Global Food Security. 2014. - No 3. - P. 133-141. - режим доступа: http://dx.doi.org/10.1016/j.gfs.2014.10.007

5. Suhara M. Russian Agricultural Statistics. March 2017. [Электронный pecypc]: Russian Research Center. The Institute of Economic Research. Hitotsubashi University. Tokyo. - режим доступа: https://hermes-ir.lib.hitu.ac.jp/rs/bitstream/10086/28395/1/RRC_WP_No67.pdf

6. Субботина Л.В. Значение ВСХП-2016 для обеспечения развития сельскохозяйственного производства в личных подсобных хозяйствах населения Курганской области [Электронный ресурс] // Инновационная наука. - 2016. - №5. -С.178-180.-режим доступа: https://elibrary.ru/download/elibrary_25994666_22160165.pdf

7. Фадеева О.П. Штрихи к фермерскому проекту: алтайская палитра // Крестьяноведение. - 2018. - Т.3. №1. - С. 141-171.

8. Итоги Всероссийской сельскохозяйственной переписи 2006 года. (Т. 1., кн. 2, Т. 2., Т. 6.) [Электронный ресурс]: режим доступа: http://www.gks.ru/news/perepis2006/totals-osn.htm

9. Итоги Всероссийской сельскохозяйственной переписи 2016 года. (Т. 1., кн. 2, Т. 2., Т. 6.) [Электронный peсурс]: режим доступа: http://www.gks.ru/free_doc/new_site/business/sx/vsxp2014/ vsxp2016.html

10. Информационный центр After shock [Электронный ресурс]: режим доступа: https://aftershock.news/? $\mathrm{q}=$ node $/ 455394 \&$ full

Сведения об авторах:

Габдрахманова Гульнара Фаатовна - доктор социологических наук, доцент, заведующая отделом этнологических исследований, e-mail: medi54375@mail.ru

Сагдиева Эльвина Азадовна - кандидат социологических наук, старший научный сотрудник отдела этнологических исследований, e-mail: elvina_n@inbox.ru

«Института истории» им. Ш.Марджани Академии наук Республики Татарстан, г. Казань, Россия.

\section{FEATURES OF ECONOMIC SUBJECTS DEVELOPMENT IN THE RUSSIAN REGIONS (ON THE EXAMPLE OF THE REPUBLIC OF TATARSTAN AND PENZA REGION) Gabdrakhmanova G.F., Sagdieva E.A.}

Abstract. The modern diversity of the agricultural sector in the constituent entities of the Russian Federation stimulates further optimization of decisions in the field of managing the country's territories. Regional differentiation is largely related to the priorities of economic entities in the formation of agricultural policy. The hypothesis is formulated in the article and arguments are presented that show that between the All-Russian agricultural censuses of 2006 and 2016 there was a further deepening of differences in the rural industry of the regions of the Russian Federation. This is manifested in the redistribution of production specializations and in the development of the resource potential of economic entities. The authors present the results of All-Russian population censuses of 2006 and 2016 in the Republic of Tatarstan and Penza region. They calculated the relative indicators of agricultural activity of agricultural organizations, peasant farms and private farms in these constituent entities of the Russian Federation. It has been revealed that Tatarstan is characterized by a soft intensification of agriculture and a policy of strengthening all business entities. In Penza region, their reduction and accelerated development of some entities is observed. In it, the surviving business entities have become more economical- 
ly sound. A comparison of the regions revealed a deepening of their production specializations. They are similar in that the rural entrepreneurship did not become a significant participant in the agricultural sector, although there is an increase in the availability of its equipment.

Key words: Republic of Tatarstan, Penza region, All-Russian Agricultural Census, resources, agricultural organization, peasant farming, personal subsidiary plots.

\section{References}

1. Federalnyy zakon ot 21.07.2005 №108-FZ (red. ot 01.12.2014) “O Vserossiyskoy selskokhozyaystvennoy perepisi”. (Federal Law of July 21, 2005 №108-FZ (as amended on December 1, 2014) "On the All-Russian Agricultural census"): Consultant Plus. - Available at: http://www.consultant.ru/document/cons_doc_LAW_54521/

2. Bartova E.V., Radosteva E.M., Galeev M.M. The importance of the agricultural census for the development of the agricultural sector of the Russian economy. [Znachenie selskokhozyaystvennoy perepisi dlya razvitiya agrarnogo sektora ekonomiki Rossii]. // Ekonomika i predprinimatelstvo. - Economics and Entrepreneurship. - 2015. - №6. - 3(59). - P. 104107.

3. Petrikov A.V. Itogi Vserossiyskoy selskokhozyaystvennoy perepisi 2016 goda: osnovne strukturne izmeneniya $v$ selskom khozyaystve Rossii za 10 let. // Moskovskiy ekonomicheskiy zhurnal. (The results of 2016 year All-Russian Agricultural Census: the main structural changes in Russian agriculture over 10 years. // Moscow Economic Journal). 2017. №4. - Available at: http://qje.su/selskohozyajstvennye-nauki/moskovskij-ekonomicheskij-zhurnal-4-2017-64/

4. Schierhorn F., Müller D., Prishchepov A., Faramarzic M., Balmann A. The potential of Russia to increase its wheat production through cropland expansion and intensification. // Global Food Security. - 2014. - No 3. - P. 133-141. - Available at: http://dx.doi.org/10.1016/j.gfs.2014.10.007

5. Suhara M. Russian Agricultural Statistics. March 2017: Russian Research Center. The Institute of Economic Research. Hitotsubashi University. Tokyo. - Available at: https://hermes-ir.lib.hit-u.ac.jp/rs/bitstream/10086/28395/1/ RRC_WP_No67.pdf

6. Subbotina L.V. Znachenie VSKhP-2016 dlya obespecheniya razvitiya selskokhozyaystvennogo proizvodstva $v$ lichnykh podsobnykh khozyaystvakh naseleniya Kurganskoy oblasti. // Innovatsionnaya nauka. (The value of VShP-2016 for ensuring the development of agricultural production in personal subsidiary plots of the population of the Kurgan region. // Innovative science). - 2016. - №5. - P. 178-180. - Available at: https://elibrary.ru/download/ elibrary_25994666_22160165.pdf

7. Fadeeva O.P. Strokes to a farming project: Altai palette. [Shtrikhi k fermerskomu proektu: altayskaya palitra]. // Krestyanovedenie. - Peasant studies. 2018. Vol. 3. №1. P. 141-171.

8. Itogi Vserossiyskoy selskokhozyaystvennoy perepisi 2006 goda. (T. 1., kn. 2, T. 2., T. 6.). Results of All-Russian Agricultural Census of 2006. (T. 1., book 2, T. 2., T. 6.) [Electronic resource]rezhim dostupa: http://www.gks.ru/news/ perepis2006/totals-osn.htm

9. Itogi Vserossiyskoy selskokhozyaystvennoy perepisi 2016 goda. (T. 1., kn. 2, T. 2., T. 6.). (Results of 2016 year of All-Russian Agricultural Census). (Vol.1., Book 2, Vol. 2., Vol. 6.)). Available at: http://www.gks.ru/free_doc/new_site/ business/sx/vsxp2014/vsxp2016.html

10. Informatsionnyy tsentr After shock. [Information center After shock]. Available at: https://aftershock.news/? $\mathrm{q}=$ node $/ 455394 \&$ full

Authors:

Gabdrakhmanova Gulnara Faatovna - Doctor of Sociology, Associate Professor, Head of Ethnological Research Department, e-mail: medi54375@mail.ru

Sagdieva Elvina Azadovna - Ph.D. of Sociological Sciences, Senior Researcher, Ethnological Research Department, email: elvina_n@inbox.ru

"Institute of History" named after Sh. Marjani, Academy of Sciences of the Republic of Tatarstan, Kazan, Russia 